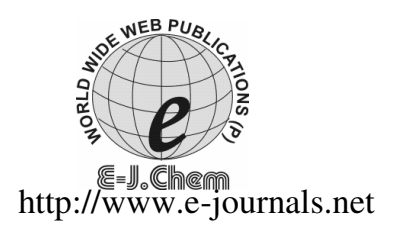

ISSN: 0973-4945; CODEN ECJHAO

E-Journal of Chemistry

2010, 7(4), 1591-1597

\title{
The Development of a New Inhibition Kinetic Spectrophotometric Method for the Determination of Phenylhydrazine Based on its Inhibitory Effect on Oxidation of Methyl Red by Bromate in Micellar Medium
}

\author{
MOHSEN KEYVANFARD \\ Faculty of Science, \\ Islamic Azad University-Majlesi Branch, Isfahan, Iran. \\ keyvan45638@yahoo.com
}

Received 15 January 2010; Accepted 10 March 2010

\begin{abstract}
A new, simple, sensitive and selective kinetic spectrophotometric method was developed for the determination of trace amounts of phenylhydrazine over the range of $0.02-0.30 \mu \mathrm{g} / \mathrm{mL}$. The method is based on the inhibitory effect of phenylhydrazine on the oxidation of methyl red by bromate in acidic and micellar medium. The reaction was monitored spectrophotometrically by measuring the decrease in absorbance of methyl red at $518 \mathrm{~nm}$ with a fixed-time 0.5-2.0 min from initiation of the reaction..The relative standard deviation of 0.08 and $0.2 \mu \mathrm{g} / \mathrm{mL}$ phenylhydrazine was 1.7 and $2.4 \%$, respectively. The method was applied to the determination of phenylhydrazine in water samples.
\end{abstract}

Keywords: Phenylhydrazine, Inhibition, Methyl Red, Micellar, Bromate.

\section{Introduction}

Phenylhydrazine, hydrazine and its derivatives are important industrial chemicals with many applications. They are used, for example, in the pharmaceutical, polymer and dye industries and in agriculture ${ }^{1}$. In addition to being reactive and explosive, phenylhydrazine is volatile and highly toxic, being readily absorbed by oral, dermal or inhalation routes of exposure. Adverse health effects on people living near hazardous waste sites caused by hydrazin and its derivatives have been described ${ }^{2}$. Contact with phenylhydrazine irritates the skin, eyes, and respiratory tract. Also, it may cause skin sensitization as well as systemic poisoning ${ }^{3}$. Therefore, the need for a sensitive, simple and reliable method for the determination of phenylhydrazine is clearly recognized. Several methods have been reported for the determination 
of phenylhydrazine. These, include titrimetry ${ }^{4}$, spectrophotometry ${ }^{5-7}$, gas chromatography ${ }^{8}$ and kinetic methods ${ }^{9-13}$. These methods either lack of sensitivity or time consuming. In order to overcome these problems, we developed and validated a rapid, sensitive and selective kinetic spectrophotometric method for the determination of phenylhydrazine.

In this paper, we developed and validated a rapid, sensitive kinetic spectrophotometric method for the determination of phenylhydrazine. Here, we report a kinetic method for trace determination of phenylhydrazine , based on its inhibitory effect on the oxidation of methyl red by $\mathrm{KBrO}_{3}$ in acidic and micellar media.

\section{Experimental}

Doubly distilled water and analytical reagent grade chemicals were used during all of the experimental studies.

Methyl red solution $3.71 \times 10^{-4} \mathrm{M}$ was prepared by dissolving $0.010 \mathrm{~g}$ of the compound (Merck) in ethanol and solution was diluted to the mark in a $100 \mathrm{~mL}$ volumetric flask.

Bromate stock solution $0.010 \mathrm{M}$, was prepared by dissolving $0.167 \mathrm{~g}$ of potassium iodate $(\mathrm{M}=214)$ in water and diluting to $100 \mathrm{~mL}$ in a $100 \mathrm{~mL}$ volumetric flask.

Standard stock phenylhydrazine solution $(10000 \mu \mathrm{g} / \mathrm{mL})$ was prepared by dissolving $4.5 \mathrm{~mL}$ of phenylhydrazine in water and diluted to $500 \mathrm{~mL}$ in a $500 \mathrm{~mL}$ volumetric flask.

Hydrochloric acid solution was prepared by appropriate dilution of concentrated hydrochloric acid (Merck).

Cetyl trimethyl ammonium bromide (CTAB) stock solution $0.0130 \mathrm{M}$,was prepared by dissolving $1.197 \mathrm{~g} \mathrm{CTAB}(\mathrm{BDH})$ in water and diluted to the mark with water in a $250 \mathrm{~mL}$ volumetric flask. The other surfactants tested, namely, cetylpyridinium chloride (CPC), sodium dodecyl sulfate(SDS) and triton- $x-100$ were prepared in a similar way.

Stock solution $(1000 \mu \mathrm{g} / \mathrm{mL})$ of interfering ions were prepared by dissolving suitable salts in water, hydrochloric acid, or sodium hydroxide solution.

All glassware were cleaned with detergent solution, rinsed with tap water, soaked in dilute $\mathrm{HNO}_{3}$ solution $(2 \% \mathrm{~V} / \mathrm{V})$, rinsed with water and dried.

\section{Apparatus}

Absorption spectra were recorded with a CECIL model 7500 spectrophotometer with a $1.0 \mathrm{~cm}$ quartz cell. A model 2501 CECIL Spectrophotometer with $1.0 \mathrm{~cm}$ glass cuvettes was used to measure the absorbance at a fixed wavelength of at $518 \mathrm{~nm}$. A thermostat water bath (Gallen Kamp Griffin, BGL 240 V) was used to keep the reaction temperature at $27{ }^{\circ} \mathrm{C}$. A stopwatch was used for recording the reaction times.

\section{Recommended procedure}

All the Solutions and distilled water were kept in a thermostated water batch at $27{ }^{\circ} \mathrm{C}$ for 20 min for equilibration before starting the experiment. An aliquot of the solution containing $0.20-3.0 \mu \mathrm{g} / \mathrm{mL}$ phenylhydrazine was transferred into a $10 \mathrm{~mL}$ volumetric flask, and then 0.3 $\mathrm{mL} 2.0 \mathrm{M} \mathrm{HCl} 2.6 \mathrm{~mL} 0.013 \mathrm{M} \mathrm{CTAB}$ and $1.4 \mathrm{~mL} 3.71 \times 10^{-4} \mathrm{M}$ methyl red were added to the flask.The solution was diluted to ca. $8 \mathrm{~mL}$ with water. Then, $0.3 \mathrm{~mL} 0.010 \mathrm{M}$ Bromate was added and the solution was diluted to the mark with water. The solution was mixed and a portion of the solution was transferred to the spectrophotometer cell. The reaction was followed by measuring the decrease in absorbance of the solution against water at $518 \mathrm{~nm}$ 
for 0.5-2.0 min from initiation of the reaction. This signal (sample signal) was labeled as $\Delta \mathrm{A}_{\mathrm{s}}$. The same procedure was repeated without addition of phenylhydrazine solution and the signal (blank signal) was labeled as $\Delta \mathrm{A}_{\mathrm{b}}$. Time was measured just after the addition of last drop of phenylhydrazine. Analytical signal was the difference between blank signal and sample signal $\left(\Delta \mathrm{A}_{\mathrm{b}}-\Delta \mathrm{A}_{\mathrm{s}}\right)$.

\section{Results and Discussion}

methyl red undergoes a oxidation reaction with bromate in acidic and micellar medium to from a colorless product at very fast rate. We found that trace amount of phenylhydrazine have a inhibitory effect on the this reaction. Therefore, by measuring the decrease in absorbance of methyl red for a fixed time of $0.5-2.0 \mathrm{~min}$ initiation of the reaction, the phenylhydrazine contents in the sample can be measured. Figure 1 shows the relationship between $\mathrm{A}$ and reaction time and also Figure 2 shows the structure of methyl red.

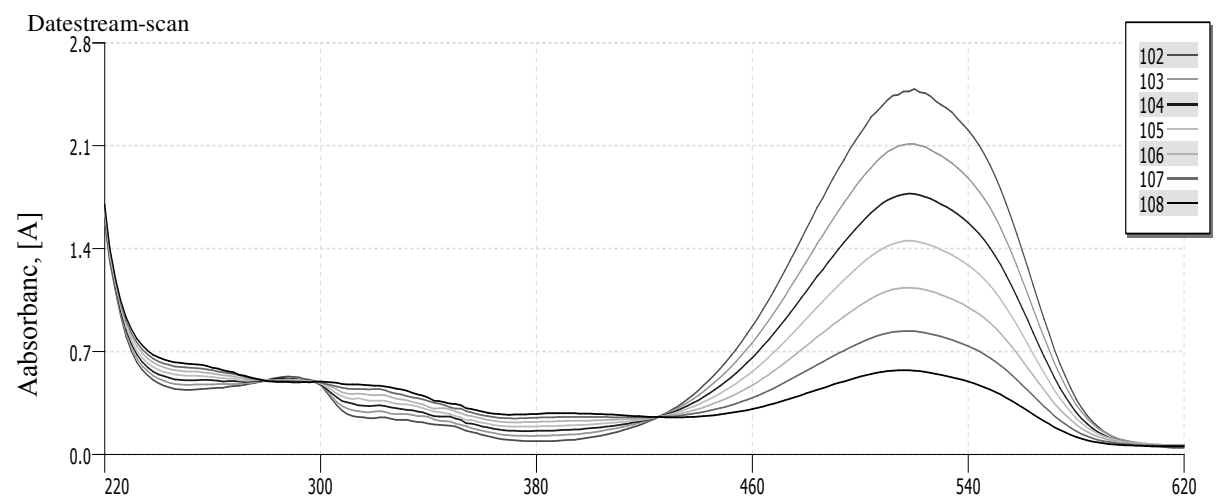

Figure 1. Absorption spectrum for the phenylhydrazine-methyl red- $\mathrm{BrO}_{3}$ system with time. Conditions: $\mathrm{HCl} 0.06 \mathrm{M}$, methyl red $5.1 \times 10^{-5} \mathrm{M} ; \mathrm{BrO}_{3}^{-} 2 \times 10^{-4} \mathrm{M}$; phenylhydrazine, $0.1 \mu \mathrm{g} / \mathrm{mL}$; temperature $27^{\circ} \mathrm{C}$; interval time for each scan, $0.5,1.5,2.5,3.5,4.5,5.5$ and 6.5 min from initiation of the reaction.<smiles>CN(C)c1ccc(/N=N/c2ccccc2C(=O)O)cc1</smiles>

\section{Influence of variables}

Figure 2. Structure of methyl red.

In order to take full advantage of the procedure, the reagent concentrations must be optimized. The effect of acid concentration, methyl red and bromate concentration, type of surfactants and temperature on analytical signal was studied. In many reactions, Suitable micelles can affect the rate of reactions ${ }^{14-21}$. A micelle usually can be formed by aggregation of a charged organic molecules. These micelles have the same charge at the outer sphere. For those reactions which have charged species, these micelles can affect the rate of reaction by increasing the effective collisions. The accelerating effect of micelles arises essentially from electrostatic and hydrophobic interactions between the reactants and micellar surface ${ }^{22}$. Cationic (CPC, CTAB), anionic (SDS) and nonionic (Triton X-100) micelles were tested at a concentration greater than that critical micelle concentration (c.m.c). The results are shown in Table 1 
Table 1. Surfactant tested for enhancment of analytical signal of methyl red $-\mathrm{BrO}_{3}^{-}$phenylhydrazine system

\begin{tabular}{cccc}
\hline Surfactant & Type & CMC, M & Micellar Effect \\
\hline SDS & Anionic & $8.1 \times 10^{-3}$ & Neutral \\
CTAB & Cationic & $1.3 \times 10^{-3}$ & Positive \\
CPC & Cationic & $1.2 \times 10^{-4}$ & Positive \\
Triton-x & Nonionic & $3.0 \times 10^{-4}$ & Negative \\
\hline
\end{tabular}

Beeween these micelles, CTAB and CPC have a positive effect but CTAB has a more positive effect than CPC, therfore CTAB was selected for practical purpose. The results show that in the presence of $\mathrm{CTAB}$, phenylhydrazine have an inhibitory effect on the oxidation of methyl red by bromate. Thus CTAB was chosen for the study. The effect of hydrochloric acid concentration on the analytical signal was studied in the range of 0.04-0.12 M. (Figure 3).

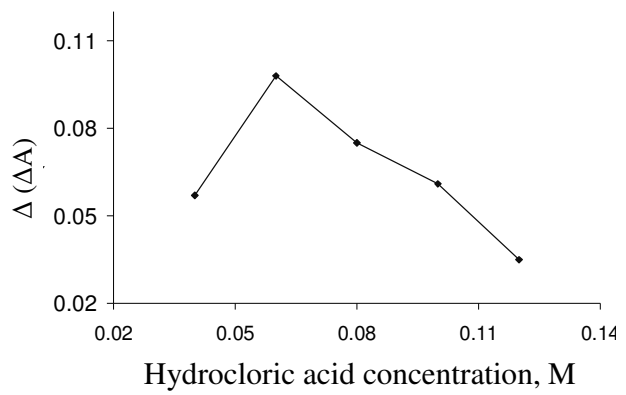

Figure 3. Influence of $\mathrm{HCl}$ concentration on the analytical signal, conditions: Methyl red $3.7 \times 10^{-5} \mathrm{M} ; \mathrm{BrO}_{3}^{-} 2 \times 10^{-4} \mathrm{M}$; CTAB $2.6 \times 10^{-3} \mathrm{M}$; phenylhydrazine, $0.1 \mu \mathrm{g} / \mathrm{mL}$; temperature $27^{\circ} \mathrm{C}$ The results show that the analytical signal increases with increasing hydrochloric acid concentration up to $0.06 \mathrm{M}$ and decreases at higher concentrations. Therefore, a hydrochloric acid concentration of $0.06 \mathrm{M}$ was selected for further study. The influence of methyl red concentration on the analytical signal was studied in the concentration range of $2.2 \times 10^{-5}-7.4 \times 10^{-5} \mathrm{M}$ (Figure 4).

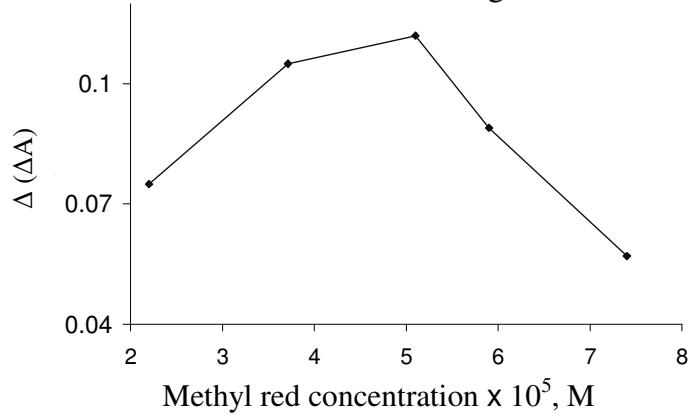

Figure 4. Effect of methyl red concentration on the analytical signal. Conditions: $\mathrm{HCl} 0.06 \mathrm{M}$, $\mathrm{BrO}_{3}{ }^{-} 2 \times 10^{-4} \mathrm{M}$; CTAB $2.6 \times 10^{-3} \mathrm{M}$; phenylhydrazine, $0.1 \mu \mathrm{g} / \mathrm{mL}$; temperature $2{ }^{\circ} \mathrm{C}$

The results show that analytical signal increases with increasing methyl red concentration up to $5.1 \times 10-5 \mathrm{M}$ and decreases at higher concentrations..Therefore, a methyl red concentration of $5.1 \times 10-5 \mathrm{M}$ was selected for further study. Figure 5 shows the effect of the bromate concentration on the analytical signal for the range of $1 \times 10-4-6.0 \times 10-4 \mathrm{M}$. This analytical signal increases with increasing bromate concentration up to $2.0 \times 10-4 \mathrm{M}$ and decreases at higher concentrations. Therefore, a final concentration of $2.0 \times 10-4 \mathrm{M}$ of bromate was selected as the optimum concentration. 


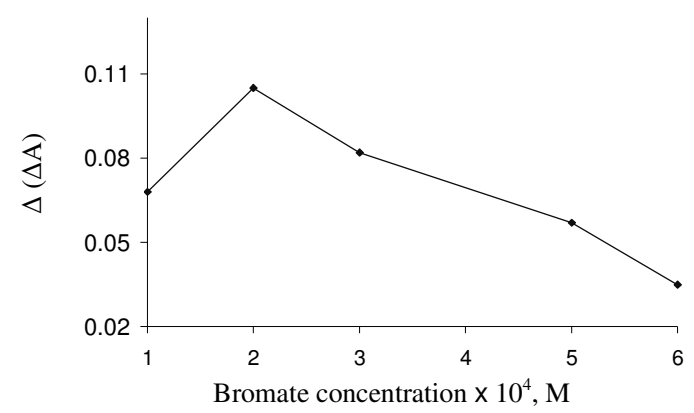

Figure 5. Effect of Bromate concentration on the analytical signal, conditions: $\mathrm{HCl} 0.06 \mathrm{M}$, methyl red $5.1 \times 10^{-5} \mathrm{M}$; CTAB $2.6 \times 10^{-3} \mathrm{M}$; phenylhydrazine, $0.1 \mu \mathrm{g} / \mathrm{mL}$; temperature $27{ }^{\circ} \mathrm{C}$

Figure 6 shows the effect of the CTAB concentration on the analytical signal for the range of $0-3.9 \times 10^{-3} \mathrm{M}$. Analytical signal increases with increasing CTAB concentration up to $3.4 \times 10^{-3} \mathrm{M}$ and decreases at higher concentrations. Therefore, a final concentration of $3.4 \times 10^{-3} \mathrm{M}$ of CTAB was selected as the optimum concentration.

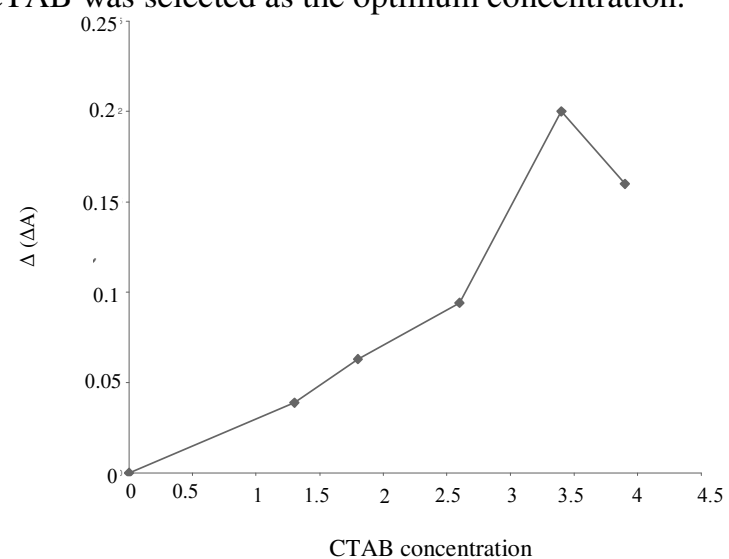

Figure 6. Effect of $\mathrm{CTAB}$ concentration on the analytical signal, conditions: $\mathrm{HCl} 0.06 \mathrm{M}$, methyl red $5.1 \times 10^{-5} \mathrm{M}$; $\mathrm{BrO}_{3}^{-} 2 \times 10^{-4} \mathrm{M}$;phenylhydrazine, $0.1 \mu \mathrm{g} / \mathrm{mL}$; temperature $27^{\circ} \mathrm{C}$

The effect of the temperature on the analytical signal was studied in the range $20-45{ }^{\circ} \mathrm{C}$ with the optimum of the reagents concentrations. The results showed that, as the temperature increases up to $27{ }^{\circ} \mathrm{C}$, the analytical signal increases, whereas higher temperature values decrease the analytical signal $\left(\Delta \mathrm{A}=\Delta \mathrm{A}_{\mathrm{b}}-\Delta \mathrm{A}_{\mathrm{s}}\right)$. Therefore, $27^{\circ} \mathrm{C}$ was selected for further study.

\section{Calibration graph, precision and limit of detection}

Calibration graph were obtained using the fixed-time method. This method was applied to the change in absorbance over an interval of 0.5-2.0 min from intiation of the reaction because it provided the best regression and sensitivity. Under the optimum conditions described above, a linear calibration range $0.020-0.30 \mu \mathrm{g} / \mathrm{mL}$ of phenylhydrazine. The equation of the calibration graph is $\Delta \mathrm{A}=0.4587 \mathrm{C}+0.1228(\mathrm{n}=7, \mathrm{r}=0.9997)$. The calibration graph was plotted by $\Delta \mathrm{A}=\Delta \mathrm{A}_{\mathrm{b}^{-}} \Delta \mathrm{A}_{\mathrm{s}}$ at a fixed -time method versus phenylhydrazine concentration. The experimental $3 \delta$ limit of detection was $0.009 \mu \mathrm{g} / \mathrm{mL}$. The relative standard deviation for six replicate determination of 0.08 and $0.2 \mathrm{ng} / \mathrm{mL}$ iodide was 1.7 and $2.4 \%$ respectively. 


\section{Interference study}

In order to assess the application of the proposed method to synthetic samples, the effect of various ions on the determination of $0.1 \mu \mathrm{g} / \mathrm{mL}$ phenylhydrazine was studied. The tolerance limit was defined as the concentration of a added ions causing a relative error less than $3 \%$ the results are summarized in Table 2 . The results show that method is relatively selective for Phenylhydrazine determination.

Table 2. Effect of foreign ions on the determination of $0.10 \mu \mathrm{g} / \mathrm{mL}$ phenylhydrazine

\begin{tabular}{cc}
\hline Foreign species & $\begin{array}{c}\text { Tolerated ratio } \\
W_{\text {species }} / W_{\text {Phenylhydrazine }}\end{array}$ \\
\hline $\mathrm{C}_{2} \mathrm{O}_{4}{ }^{-2}, \mathrm{HSO}_{4}{ }^{-}, \mathrm{HCO}_{3}{ }^{-}, \mathrm{CO}_{3}{ }^{2-}, \mathrm{SO}_{3}{ }^{2-}$, & \\
Tatarate, $\mathrm{CH}_{3} \mathrm{COO}^{-}, \mathrm{BO}_{3}{ }^{3-}, \mathrm{Na}^{+}, \mathrm{K}^{+}, \mathrm{Ca}^{2+}$, & 1000 \\
$\mathrm{Mg}^{2+}, \mathrm{Rb}^{+}, \mathrm{Zn}(\mathrm{II}), \mathrm{Ba}^{+} \mathrm{Cr}(\mathrm{III}), \mathrm{Pb}(\mathrm{II}) \mathrm{Pd}(\mathrm{II})$ & \\
$\mathrm{Cu}(\mathrm{II}), \mathrm{IO}_{3}{ }^{-}, \mathrm{ClO}_{3}$ & 800 \\
$\mathrm{SCN}^{-}, \mathrm{S}_{2} \mathrm{O}_{8}{ }^{2-} \mathrm{S}_{2} \mathrm{O}_{8}{ }^{2-}$ & 200 \\
$\mathrm{Hg}^{+2}, \mathrm{Ni}^{2}(\mathrm{II}), \mathrm{Co}(\mathrm{II})$ & 100 \\
$\mathrm{~N}_{2} \mathrm{H}_{4}$ & Inhibited \\
\hline
\end{tabular}

\section{Sample analysis}

In order to evaluate the applicability of the proposed method, water samples and synthetic water samples were analyzed to determine phenylhydrazine contents. The results are presented in Table 2. Good recoveries with precise results show good reproducibility and accuracy of the method. Table 2

Table 3. Determination of phenylhydrazine in real samples

\begin{tabular}{ccccc}
\hline Sample & $\begin{array}{c}\text { Phenylhydrazine } \\
\text { added, } \mu \mathrm{g} / \mathrm{mL}\end{array}$ & $\begin{array}{c}\text { Phenylhydrazine } \\
\text { found, } \mu \mathrm{g} / \mathrm{mL}\end{array}$ & $\begin{array}{c}\text { Recovery } \\
\%\end{array}$ & $\begin{array}{c}\text { RSD } \\
\% \mathrm{n}=3\end{array}$ \\
\hline Well water & 0.080 & 0.086 & 107.5 & 1.8 \\
Well water & 0.140 & 0.128 & 91.4 & 2.1 \\
Well water & 0.240 & 0.253 & 105.4 & 2.5 \\
\hline
\end{tabular}

\section{Conclusion}

The kinetic method developed for the determination of phenylhydrazine is inexpensive, uses readily available reagents, allows rapid determination at low operating costs and shows simplicity, adequate selectivity, low limit of detection and good precision and accuracy compared to other kinetic procedures. The detection limit of the proposed method in comparison with reported methods was better (Table 4).

Table 4. Comparison of kinetic spectrophotometry methods for the determination of phenylhydrazine with proposed method

\begin{tabular}{cccc}
\hline Method & $\mathrm{DL}, \mu \mathrm{g} / \mathrm{mL}$ & $\mathrm{LDR}, \mu \mathrm{g} / \mathrm{mL}$ & reference no. \\
\hline Kinetic spectrophotometry & - & $3-10$ & 11 \\
Kinetic spectrophotometry & 0.05 & $0.2-10$ & 12 \\
Kinetic spectrophotometry & 0.02 & $0.05-8$ & 13 \\
Kinetic spectrophotometry & 0.02 & $0.05-8$ & 13 \\
Proposed method & 0.009 & $0.02-0.3$ & - \\
\hline
\end{tabular}




\section{Acknowledgments}

The author are Thankful to the Islamic Azad University-Majlesi Branch for the support of this work.

\section{References}

1. Hawley G G, The Condensed Chemical Dictionary, Van Nosttrand -Reinhold, New York, 1981.

2. Choudhary G and Hansen H, Chemosphere, 1998, 37, 801-843.

3. Sax N I, Dangerous Properties of Industrial Materials, $4^{\text {th }}$ Ed., van NostrandReinhold, New York, 1975.

4. Besada A, Anal Lett., 1988, 21, 1917.

5. Murty K K, Rao V J and Rao N V S, Talanta, 1984, 31, 466.

6. Hasan T, Anal Lett., 1988, 21, 633-640.

7. Yatsimirsky A K, Yatsimirskaya N T and Kashina S B, Zh Anal Khim., 1994, 66, 2232.

8. Mosinska K, Chem Anal (Warsaw)., 1980, 25, 859.

9. Gutierrez M C, Gomez-Hens A and Perez-Bendito D, Anal Chim Acta., 1989, 255, 115.

10. Mitic S D, Nhkolic S D and Stankov-Jovanovic V, J Serb Chem Soc., 2005, 70, 987.

11. Afkhami A and Bahram M, Talanta, 2006, 68, 1148.

12. Afkhami A and Zarei A R, Talanta, 2004, 62, 559.

13. Afkhami A and Assl A A, Mcirochem J., .2001, 69, 51.

14. Ensafi A A and Keyvanfard M, Anal Lett.,2000, 35, 423.

15. Ensafi A A and Keyvanfard M, Int J Environ Anal Chem., 2002, 83, 397.

16. Ensafi A A and Keyvanfard M, J Anal Chem., 2003, 58, 1060.

17. Keyvanfard M and Karamian M, Asian J Chem., 2009, 21(2), 942.

18. Keyvanfard M, Asian J Chem., 2009, 21, 2715.

19. Keyvanfard M, Asian J Chem., 2009, 21(2), 983.

20. Keyvanfard M, Asian J Chem., 2009, 21(2), 989-996.

21. Keyvanfard M, Asian J Chem., 2009, 21, 2119.

22. Rubio S and Perez-Bendito D, Anal Chem Acta., 1989, 224, 185. 


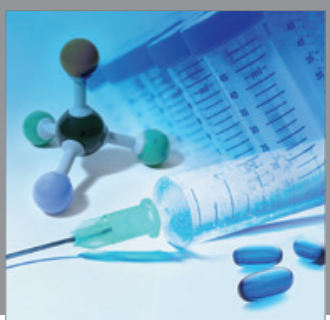

International Journal of

Medicinal Chemistry

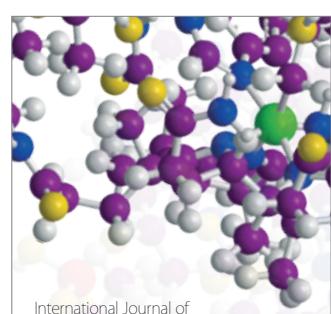

Carbohydrate Chemistry

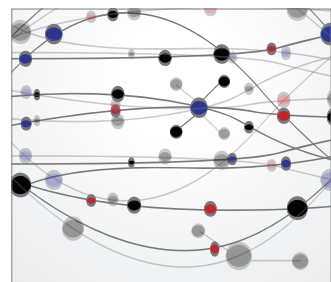

The Scientific World Journal
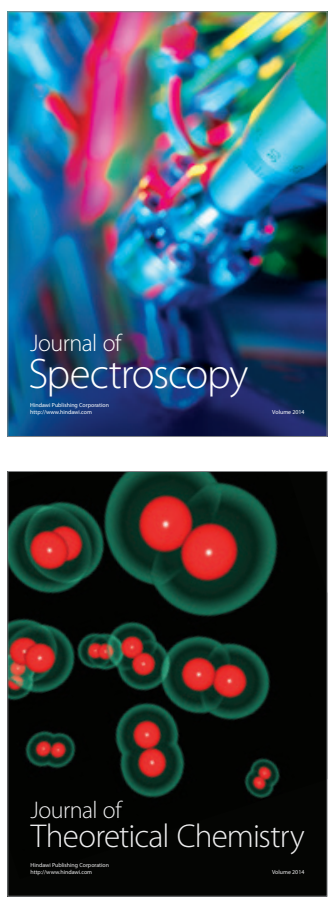
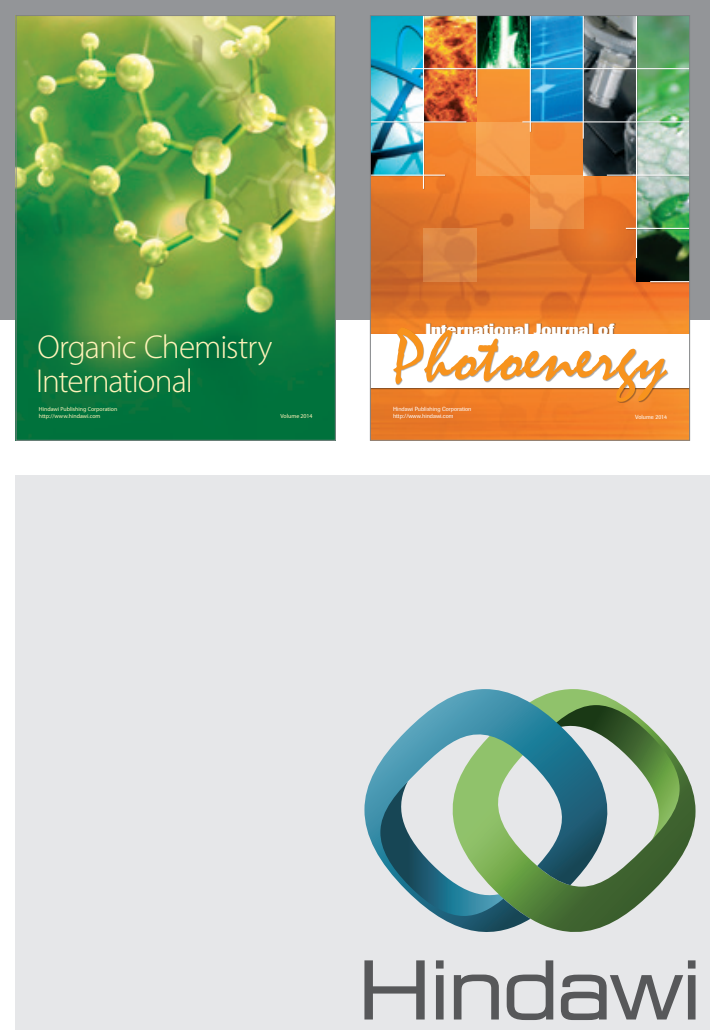

Submit your manuscripts at

http://www.hindawi.com
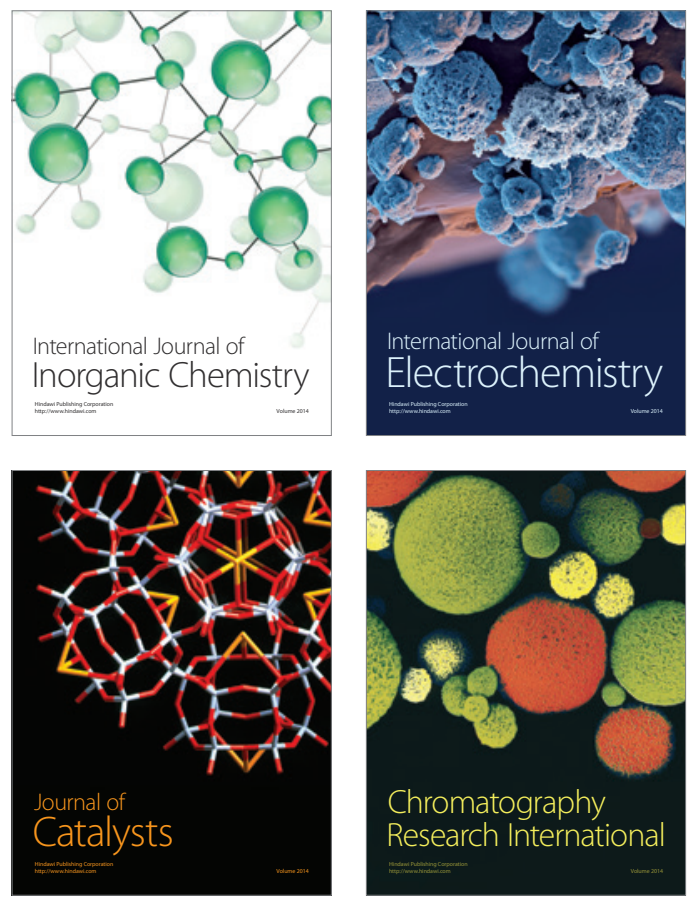
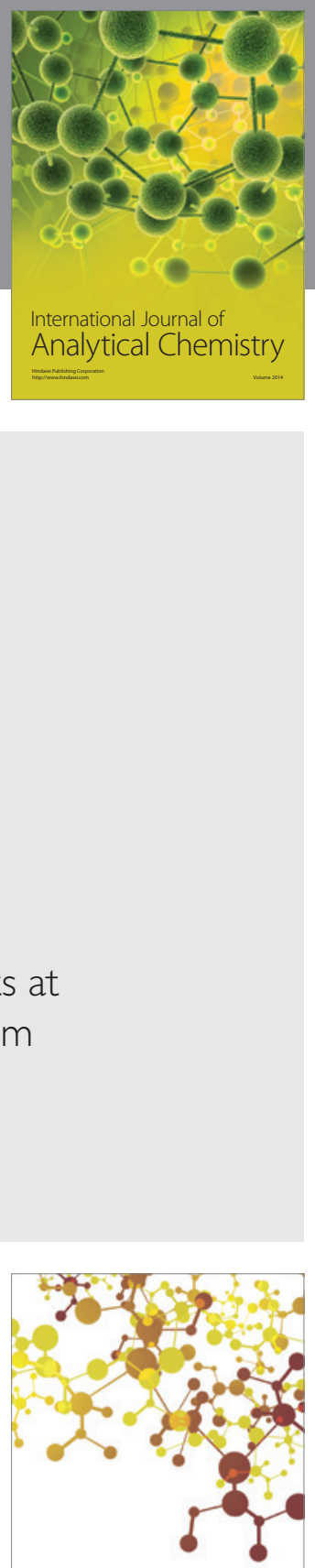

Journal of

Applied Chemistry
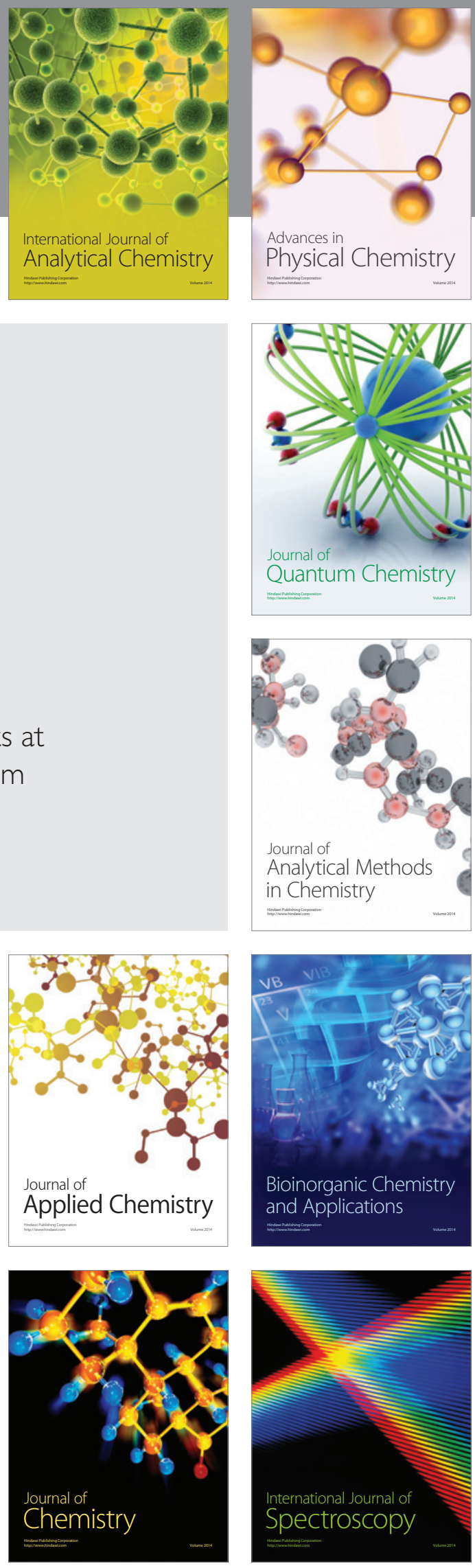